\title{
Pricing Policies in a Dual-channel Supply Chain with Manufacture Services
}

\author{
J.F. Tian, T.J. Fan \\ Business School of East China University of Science and \\ Technology \\ Shanghai, China
}

\begin{abstract}
With the rapid development of network and information technology, online channel as a new business model has improved the structure of offline channel, but also caused a huge impact on offline channel, channel competition has entered the online channel. Manufacturer in this paper has only one online channel, retailer has both traditional distribution channel and online channel, we establish two game models based on Stackelberg game and Bertrand game separately. Our models focuse on the manufacturer's and the retailers' competition strategy of price under different service quality. Finally, we analyze the manufacturer's and the retailer's profit by numerical experiment. Numerical results reveal that the more consumers give perference to online channel, the lower prices are. With the improvement of service quality, the prices of both side increase. Although the retailer does not provide any service, but by raising the price of it's products, it can benefit from the manufacture's service. The manufacturer always prefers to be the price leader.
\end{abstract} game

Keywords-dual channel supply chain; pricing; service quality;

\section{INTRODUCTION}

The data from the China electronic commerce research center shows that Chinese online retail sales has achieved 754.2 billion yuan as of June 2013, it is $6.8 \%$ of the total retail sales of social goods and is expected to reach $7 \%$ by the end of 2013. Forrester research points out that the online retail sales in 2007 reached $\$ 175$ billion, it up 13\% from 2007 to 2008 and expected to reach $\$ 229$ billion in 2013. Thus, the demand on online channels is huge. Companies had built their "nets" on the basis of the experience of offline store ability. IBM, HP, Nike, SONY, Wal-mart and other companies have implemented this new business model and made great achievements. The combination of online and offline channels in supply chain has became a new trend.

When increase one online channel, the structure of supply chain will be changed. Manufacturer has a double identity: one is the supplier of retailer, the other is retailer's direct competitor. Due to the limited market share, it makes the channel conflict inevitably. Such as the 1990s, Home Depot said publicly that if the supplier built online channel, Home Depot will cancel its strategic cooperation with the supplier[1]. At the same time, how to effectively reduce the channel conflict and achieve a win-win result are worthy of study.

\author{
J.L. Hu \\ Shanghai university of political science and law \\ Shanghai, China
}

Webb[2] pointed out that pricing is the key factor of channel conflict. Pricing depends on the consumers' purchase decision, the consumers' purchase decision is mainly affected by price and service quality. In general, the price is negatively related to the actual demand, the service quality is actively related to the actual demand. Such service include: the installation of the product, maintenance, guarantee work, after service, information and other online services, etc. The service provider can be manfacturer, retailer or both sides[3]. How to achieve supply chain balance with price and service is worth exploring.

Several studies have examined dual channel supply chain. These researchs mainly discuss how to pricing and achieve equilibrium . Ming-hui $x{ }^{[3]}$ analysis pricing decision by different service providers under Stackellberg and Nash game. He points out that both sides can benefit a lot under the stacellberg game when service is provided to customers and the service provider benefit only under certain conditions in Nash game. Sun Yangong [4] studies the manufacturer's optimal channel selection strategy and the influence of the online channel on offline channel. Dan [5] focues on pricing with the service quality and consumer loyalty, the result is service provided by retailer has a significant impact on pricing. Huag [6] studies pricing decision of both manufacturer and retailer. Research suggests that the delivery time has significant effects on pricing decesion and profit. Kurata $\mathrm{H}$ [7] studies pricing decision in dual-channel supply chain. He focuses on brand and Channel competition. Chen [8] discusses competition between delivery time and product availability. Rhee [9] studies pricing decision under different service quality, he points out that manufacturer will avoid price competition and focus on service work when the service sensitive consumers have higher valuation for retail services. Mukhopadhyay [10] points out that the retailer's value-added services can effectively reduce channel conflict in the high-tech industry. Meiling luo[11] studies he optimal strategy when manufacturer provides value-added services, she shows that the introduction of value-added services can help to reduce the double marginal effect and expand market demand, but it will reduce retailer's profit.

These researches get valuable conclusions from different angles, but there are limitations: the supply chain structure mostly is retailer who has double channels or manufacturer who has double channels. For the mode that manufacturer has one online channel and retailer has both online and offline channels, few existing literature study. We study pricing decision with service quality in the new supply chain structure 
under Stackelberg and Bertrand game. Then, by numerical experiments, we analyze price and profit trends under the different service quality .

\section{THE MODEL}

The dual-channel supply chain is shown as figure 1 . We consider a single product model with a manfacturer and a retailer. The manfacturer sells to the retailer as well as to the consumers directly. Consumers may choose the retailer (online or offline channels) or the manfacturer (online channel) to get the good. We begin with describing the consumer choice process. Consumer utility is affected by product price and the manufacturer's service quality.

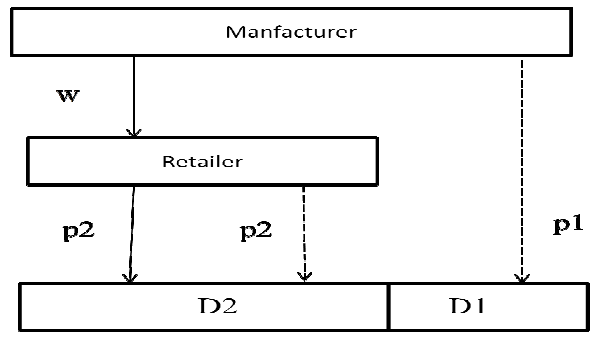

FIGURE I. DUAL-CHANNEL SUPPLY CHAIN.

Note: (1)The dotted line means the online channel, the solid line is the offline channel.

(2) In order to weaken the channel conflict, there are about two-thirds of the manufacturers to keep price equal in online channel and offline channel [12], this paper assumes that the retailer online channel prices is equal to the offline channel. In reality, there are retailers to keep online price equal to offline channel, such as SuNing.

We model an individual consumers' unility $\mathrm{u}_{\mathrm{i}}$ as a function of both price and service. The consumer choose the channel that maximizes her unility.

$$
\mathrm{u}_{i}=\mathrm{v}+\theta s_{i}-p_{i}
$$

Furthermore, we present :

(1)Let $\mathrm{p}_{1}$ and $\mathrm{p}_{2}$ denote the unit price at the retailer's channel and the manfacturer's channel. Let $\mathrm{s}$ denote the service quality offered by the manfacturer. Service cost is marked as $\mathrm{c}_{\mathrm{s}} . \eta$ is constant.

$$
c_{\mathrm{s}}=\frac{\eta \mathrm{s}^{2}}{2}
$$

(2) v means the consumers' valuation of the product.

(3) Consumers can obtain product more convenient, more abundant product information and no time constraint frome online channel. When it comes to offline channel, it neans low risk and facilitate the actual inspection and the advantages of the products without waiting for distribution. Different customers have different channel preference.In this paper, we assume that the market size is 1 and consumers who perfer to buy product frome online channel (retailer or manfacturer) is $\mathrm{m}$. Other consumers who perfer to buy product frome offline is $1-m$.

(4) Different consumers have different sensitivity to the service quality offered by the manfacturer. We present this sensitivity by $\theta . \theta$ is randomly drawn frome a uniform distribution with support on [0,1].For the consumer who has a perference on online channel, there is no difference between manfacturer online channel and retailer online channel if and only if $\mathrm{u} 1=\mathrm{u} 2$. Thus, a consumer with $\theta^{*}$ is indifferent between the two channels. Consumers with $\theta<\theta^{*}$ choose online channel of the retailer, Consumers with $\theta>\theta^{*}$ choose online channel of the manfacturer, others choose offline channel of retailer.

$$
\theta^{*}=\frac{p_{1}-p_{2}}{s}
$$

(5) In order to have non-zero channel demands, we need to have $v-p_{2}>v-p_{1}$ and $v-p_{2}<v+s-p_{1}$. Others, we need to have $v-p 1>0$ and $v-p 2>0$ to make sure that each consumer has a positive effect. So $\mathrm{p}_{2}<\mathrm{p}_{1}, \mathrm{p}_{2}>\mathrm{p}_{1}$-S.

(6)In this paper, we present $D_{1}$ and $D_{2}$ as market demand of the manufacturer and the retailer.

Therefore, the demand functions for the channel is

$$
\begin{gathered}
D_{1}=m^{*}\left(1-\theta^{*}\right) \\
D_{2}=1-m^{*}\left(1-\theta^{*}\right)
\end{gathered}
$$

Manufacturer's benefit comes from online sales, the retailer's revenue include online and offline sales. Therefore, we get the profit functions.

The manufacturer's profit function is

$$
\pi_{1}=\left(p_{1}-c_{s}\right) D_{1}+w D_{2}
$$

The retailer's profit function is

$$
\pi_{2}=\left(p_{2}-w\right) D_{2}
$$

\section{ANALYSIS OF THE DUAL-CHANNEL SUPPLY CHAIN MODEL}

\section{A. Optimal Pricing Decision under Stackelberg Game in the Dual-Channel Supply Chain}

In this section, we analyze the case where the retailer make decision after the manfacturer.

In the dual-channel supply chain, if the manufacturer's power is very strong, the manufacturer can conduct Stackelberg game. Stackelberg game process is as follows: The manufacturer set price to maximize his profit .Then, the retailer make decision according the manufacturer to maximize his profit. Our next result is aimed at better understanding the optimal pricing of the manfacturer and the 
retailer.

proposition1 The optimal pricing strategy for the dual-channel supply chain is $\left(\mathrm{p}_{1}{ }^{\mathrm{S}^{*}}, \mathrm{p}_{2}{ }^{\mathrm{S}^{*}}\right)$ under Stackelberg game.

$$
\begin{gathered}
p_{1}{ }^{*}=\frac{s}{2}+\frac{s}{2 m}+w+\frac{1}{4} \eta \mathrm{s}^{2} \\
p_{2}{ }^{S^{*}}=-\frac{s}{4}+\frac{3 s}{4 m}+\mathrm{w}+\frac{1}{8} \eta s^{2}
\end{gathered}
$$

\section{B. Optimal Pricing Decision under Bertrand Game in the Dual-channel Supply Chain}

In this section, we analyze the case where the manfacturer and retailer simultaneously make decision.

In the dual channel supply chain, if the manufacturer and the retailer have the same power, there is a Bertrand game between the manufacturer and the retailer. Bertrand game process is as follows: Manufacturer set price for his own profit maximization as the goal. At the same time, retailer set his own price to maximize profit. there is an equilibrium price .

proposition2 The optimal pricing strategy for the dual supply chain is $\left(\mathrm{p}_{1}{ }^{\mathrm{B}^{*}}, \mathrm{p}_{2}{ }^{\mathrm{B}^{*}}\right)$ under Bertrand game.

$$
\begin{gathered}
p_{1}^{B^{*}}=\frac{s}{3}+w+\frac{s}{3 m}+\frac{1}{3} \eta s^{2} \\
p_{2}^{B^{*}}=-\frac{s}{3}+w+\frac{2 s}{3 m}+\frac{1}{6} \eta s^{2}
\end{gathered}
$$

\section{The Optimal Decisions Comparison under Different Game in the Dual-channel Supply Chain}

According to proposition 1 and 2, when the manufacturer provids service, we get conclusions as follows..

Conclusion1 In the dual-channel supply chain, channel pricing of the manfacturer and the retailer increase along with the improvement of service quality.

That proof is as follows:

By the proposition 1, the following results are obtained.

$$
\begin{gathered}
\frac{\partial p_{1}^{s^{*}}}{\partial \mathrm{s}}=\frac{1}{2}+\frac{1}{2 m}+\frac{1}{2} \eta \mathrm{s}>0 \\
\frac{\partial p_{2}^{s^{*}}}{\partial \mathrm{s}}=-\frac{1}{4}+\frac{3}{4 m}+\frac{1}{4} \eta \mathrm{s}>0 \\
\frac{\partial p_{1}^{s^{*}}-\partial p_{2}^{s^{*}}}{\partial s}=\frac{3}{4}-\frac{1}{4 m}+\frac{1}{4} \eta \mathrm{s}>0
\end{gathered}
$$

By the proposition 2, the following results are obtained.

$$
\begin{gathered}
\frac{\partial p_{1}^{B^{*}}}{\partial s}=\frac{1}{3}+\frac{1}{3 m}+\frac{2}{3} \eta s>0 \\
\frac{\partial p_{2}^{B^{*}}}{\partial s}=-\frac{1}{3}+\frac{2}{3 m}+\frac{1}{3} \eta \mathrm{s}>0 \\
\frac{\partial p_{1}^{B^{*}}-\partial p_{2}^{B^{*}}}{\partial s}=\frac{2}{3}-\frac{1}{3 m}+\frac{1}{3} \eta s
\end{gathered}
$$

Additional details of conclusion1:Under the Stackelberg game and Bertrand game, when service quality is improved, the service cost of the manufacturer will increase and the manufacturers have to increase his price. No consumer can get free service, all of the service will eventually be paied by consumers.

The manufacturer's price will decline when service quality is droped. if the retailer choose strategy of lower price to compete with the manfacturer, the reduction of the retailer is always smaller than the manufacturer under Stackelberg game. Under Bertrand game, the reduction of the retailer is lower than the manufacturer when $\frac{1}{2+\eta_{\mathrm{s}}}<m<1$.

Conclusion2 In the dual channel supply chain, channel pricing of the manfacturer and the retailer decline along with the increase in $\mathrm{m}$.

That proof is as follows:

By the proposition 1, the following results are obtained.

$$
\begin{gathered}
\frac{\partial p_{1}^{s^{*}}}{\partial \mathrm{m}}=-\frac{s}{2 m^{2}}<0 \\
\frac{\partial p_{2}^{s^{*}}}{\partial \mathrm{m}}=-\frac{3 \mathrm{~s}}{4 m^{2}}<0 \\
\frac{\partial p_{1}^{s^{*}}-\partial p_{2}^{s^{*}}}{\partial \mathrm{m}}=\frac{s}{4 m^{2}}>0
\end{gathered}
$$

By the proposition 2, the following results are obtained.

$$
\begin{gathered}
\frac{\partial p_{1}^{B^{*}}}{\partial \mathrm{m}}=-\frac{s}{3 m^{2}}<0 \\
\frac{\partial p_{2}^{B^{*}}}{\partial m}=-\frac{2 \mathrm{~s}}{3 m^{2}}<0 \\
\frac{\partial p_{1}^{B^{*}}-\partial p_{2}^{B^{*}}}{\partial m}=\frac{s}{3 m^{2}}>0
\end{gathered}
$$

Additional details of conclusion2:The more the consumers 
who perfer to buy product from online channel, the smaller the price of the manufacturer. If the retailer choose the price competition strategy, the reduction of the retailer is always bigger than the manufacturer.

\section{NUMERICAL RESULTS}

Our objective in this section is to draw managerial insight based on a numercial analysis of our model. We illustrate our results with a mumercial example. The parameters for this example are $\mathrm{s}=0.35, \mathrm{w}=0.75, \mathrm{~m}=0.75, \eta=3$.In each section, we draw and interpret figures by varying a parameter while keeping others constant.

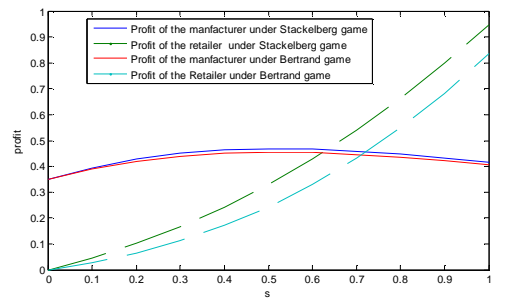

FIGURE II. EFFECT OF MANUFACTURER'S SERVICE QUALITY.

When the manufacturer's service quality is increased, the manufacturer's profit increasing rate is higher than the speed of service cost. As a whole, its profit increases with the improvement of service quality, and when the service quality is in $[0.52,1]$, their profits will decrease with the improvement of the service quality. Under the Stackelberg game, the manufacturer's profit is more and it is always willing to be the price leader. For the retailer, he has the intention to be the price leader when the servise quality is in $[0,1]$ and the retailer can get more profit.

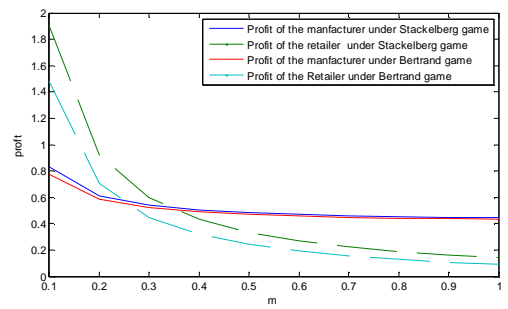

FIGURE III.

EFFECT OF CONSUMERS' PREFERENCE.

In the case, the demand in each channel is non-zero and together they cover the whole market. The manfacturer's and the retailer's profit decreased with the increase of online consumers. Thus, when online consumers is large, price competition will reduce benefits on both sides, they will avoid price competition.

\section{CONCLUSIONS}

In this paper, the object of our study is a dual supply chain where the manufacturer has only one online channel and the retailer have both online and offline channels. We focus on the problem of pricing and analyze the effect of service quality on the price and profit. We have shown the following results.

First, When the manufacturer only provides service to his consumers, the retailer can be a "free rider" ,although he does not provide any service, he can benefit from it by raising the price of product. We believe that the retailer has no willing to offer any service to his consumers.

Second, the manufacturer can get more profit under Stackelberg game. Within a certain service quality, the retailer's profit under Stackelberg game is higher than Bertrand game, under this circumstance, the retailer tend to be the manufacturer's follower. therefore, for the manufacturer, it is better to set low service quality when the manufacturer is the leader of the dual-channel supply chain.

Third, the more consumers has perference for online channel, the lower prices and profits are. Both the manfacturer and the retailer would avoid price competition. Improving service is the effective way to add profit.

\section{REFERENCES}

[1] Li Shu-juan. Pricing strategy research of dual channel supply chain considering the traders' behavior [D]; Huazhong University of Science and Technology, 2012.

[2] WEBB K L. Understanding hybrid channel conflict: a conceptual model and four case studies [D]; University of North Carolina at Chapel Hill, 1997.

[3] Xu Ming-hui, Yu Gang, Zhan Han-qing. Supply chain game analysis with service [J]. Journal of Management Sciences In China, 2006, 9(2): 18-27.

[4] Sun Yanhong, Tu Yijian,Xu Xiaoyan. Model of service competition based on the customer channel preference [J]. Journal of Management Science, 2011, 24(4): 62-70.

[5] DAN B, XU G, LIU C. Pricing policies in a dual-channel supply chain with retail services $[\mathrm{J}]$. International Journal of Production Economics, 2012, 139(1): 312-20.

[6] HUA G, WANG S, CHENG T C E. Price and lead time decisions in dual-channel supply chains [J]. European Journal of Operational Research, 2010, 205(1): 113-26.

[7] KURATA H, YAO D-Q, LIU J J. Pricing policies under direct vs. indirect channel competition and national vs. store brand competition [J]. European Journal of Operational Research, 2007, 180(1): 262-81.

[8] CHEN K-Y, KAYA M, ÖZER Ö. Dual sales channel management with service competition [J]. Manufacturing \& Service Operations Management, 2008, 10(4): 654-75.

[9] RHEE B-D, PARK S-Y. Online store as a new direct channel and emerging hybrid channel system [J]. 2000,

[10]MUKHOPADHYAY S K, YAO D-Q, YUE X. Information sharing of value-adding retailer in a mixed channel hi-tech supply chain [J]. Journal of Business Research, 2008, 61(9): 950-8.

[11]Luo Me-iling, Li Gang, Sun Lin-yan. Competition in a dual-channel supply with add-value services [J]. Industrial Engineering and Management, 2011, 16(3): 37-44.

[12]ALLEN L, COOPERSTEIN D, YOUNG D, et al. Channel conflict crumbles [M]. Forrester Research, 2000. 